\title{
MJN CARING AS UNENDING EXPRESSION OF NURSING (CUEN): A THEORY OF NURSING
}

\author{
Joel Rey U. Acob \\ Faculty of Nursing, Visayas State University, Philippines \\ Corresponding Author's Email:joel.acob@vsu.edu.ph
}

\begin{abstract}
Caring as Unending Expression of Nursing (CUEN) emerged to describe clinical nursing practice as basis to knowledge development of the discipline. This is grounded in the theory of Nursing as Caring. Concepts, theories and statements are derived-synthesized and critically analyzed using Explanatory multivariate regression tree (MRT) as an approach to develop the new theory. Based from analyses, CUEN Theory sees the person as dignified being, who lives and grows in caring environment from moment-tomoment. The person is whole and complete as he embodies the caring attitude by virtue of his humanness. The basic premise of CUEN is that all human beings are caring in nature; and that anybody showing and doing expressions of unending care is considered a nurse because to be human is to be called to live one's innate caring nature. The caring according to this theory is intentional expression of nursing care to the nursed, who is recognized as person, living, growing in caring environment. CUEN assumed that Personhood is a process of living grounded in caring and Personhood is enhanced through nurturing relationships by caring for others. The practice of CUEN becomes evident when the nurse acknowledges herself as tool for caring; communicates properly in a manner so that it transpired in the nursing situation; offers option so patient makes choices without coercion or force; and conjointly advanced to materialize the identified options. The complete execution of the recognized intervention will come to play thus creating nursing situation. It is recommended that CUEN be applied to practice for validation in the light of the different philosophical bases.
\end{abstract}

\section{Keywords: Expression of nursing, Explanatory MRT, Caring Theory, Nursing, Nursing Theory}

\section{INTRODUCTION}

The concern about the development of nursing theory and its use became evident in the early 60 's when the emphasis was on the integration of theories from other disciplines into the practice of nursing Peterson (1977). However, in the early 80's, the realization and emphasis on nursing concepts emerged and began to dominate the theoretical world of nursing. Emphasis shifted from the analysis of existing theories to the development of distinctive nursing theories Meleis (2003). Consequently, the nursing literature is replete with concerns about theories of nursing, suggesting that nursing theories ought to be congruent with a broader perspective of acceptable nursing theories for illustrating its use in the understanding of the discipline and profession of nursing. In this regard, it is critical that related descriptions of theory in nursing, its development, and use in nursing be appreciated and understood for these to be useful in growing as a profession of practice and knowledge-based discipline.

The development of a theory calls for scientific process that endeavors to facilitate knowledge in the discipline. The theory is classified as explanatory or descriptive Barnum (1998) which answers significant inquiry in a particular discipline.The descriptive theories observe a phenomenon and identify its elements and events. On the other hand, explanatory theories deal with the relationship between effect and cause, or the rules regulating interaction among constituents. Philosophy, experiences and concepts 
relative to the existing phenomena creates the concern of the nursing discipline Meleis (2003). This view is supported by Dickoff (1968) observation that the purpose of a theory is to describe and explain the practice of nursing.

In its deeper understanding, the theory will facilitate the realization of its state of acceptability of care that the nurse employs. Nursing theories are essential for guiding not only the practice's aspect of caring but even useful for education, research as well as strengthening the links among those areas of concern. Nursing theories are necessary and very important for the discipline. This describes the knowledge of nursing profession, promotes stduies that advances the knowledge of nursing and establishes direction of professional practice. Fawcett (1983) asserted that nursing theory was characterized as sets of concepts and definitions that address the metaparadigm phenomena of person, environment, health and nursing by specifying relations among variables derived from these phenomena. The nursing theory gives basis to nursing practice and is useful to describe nursing phenomenon Meleis (2003). It also helps in analyzing and explaining relationships among those phenomena, in predicting consequences, and in prescribing actions.

When writing about theory, it is imperative to consider knowledge, since knowledge development within a discipline occurs through the development of theories. Experiences and the day-to-day interactions of the nurse and client in a caring environment also provide opportunity to discover hypothesis as a single starting point to ignite theory development. The knowledge as defined is the familiarity and gained experience that equip the nurse with care perceptions and clear view of facts and truth. The knowledge acquired by the nurse through experience and practice establishes a legitimate basis for the authority of the profession; provide status and prestige that facilitates the socialization of new members of the nursing profession.

Nurses must incorporate in their mind lead questions as bases to create and develop theories. Questions such as what is nursing? When will nursing occur? Is nursing essential? Who will practice nursing, where will it occur and how will it be done?

\section{RESEARCH METHODOLOGY}

Concept development became the vital process to improve the abstract of CUEN theory. Themes from derived premise were analyzed and critically explored using Explanatory MRT as an approach to develop the new theory. The observed phenomenon were combined with years of experience as nurse practitioner and eventually the emergence of the theory of caring was brought about. It was observed that amidst scarcity of human resource and the high ration between nurse and the nursed in caring at health care settings, nurses could not possibly attend the total needs of patients. Though the nurse works and moves with dynamism, but the unique character of patients, sometimes limit the caregiver to unintentionally show reduced care. It is in this cause that the nurse educates family members and other important members on delegated tasks as an extended means of caring-leading to the development of this theory.

\section{RESULTS AND DISCUSSION}

The theory of Caring as Unending Expression of Nursing (CUEN) was anchored in the theory of Nursing as Caring Boykin \& Schoenhofer (2001). The ontology of this theory describes nursing as nurturing persons as caring by their humanness. The nurse is being dedicated to working with care, and compassion committed to helping the patient and the significant others in the spirit of caring. The nurse along the moment is attentive towards the patient and shows empathy, which makes caring as a central concept and expression of nursing. This emphasizes the primacy of competence in professional caring, as well as that of genuine concern, openness and willingness to connect others. In addition, the nurse starts to explore the real and deeper meaning of caring as the unending expression of nursing practice and distinguish it from the usual manner of intentional caring. However, the essential structure of the uncaring was encountered when the nursed failed to recognize his fullness of wellbeing and healing. The resulted in a sense of mistrust and disconnection to the health provider and the sense of ruined and despair among the patient, limits this caring theory.

The discipline of knowledge was described as a community of scholars who developed a particular perspective of the world and what it means to be in the world King, et al. (1976). Each disciplinary community holds a common denominator on a value system that was expressed in its distinctive focus of understanding and performance of a nurse. From this perspective of care, the focus of nursing was expressed as nurturing 
persons living and growing in a caring environment Schoenhofer (2001).This living and caring is personhood that means a person lives the meaning of his own life. The ultimate goal of nursing is to know the person as holistic being, to support and maintain them as they live within the context of a caring environment. Caring is an unending language of nursing and is "deliberate and genuine existence of the nurse with the nursed who was identified to grow and live in caring relationship" Boykin \& Schoenhoefer (2001). The sensitivity and skill in creating effective ways of communication with proper caring are developed gradually through intention to care.

\section{The Person}

The person is a dignified whole being and lives and grows in a caring environment. From the standpoint of nursing as caring Boykin \& Schoenhofer (1993), this person is complete, complete and integrated. There is no impartiality, no discrepancy and there is no deficiency as a whole. The analysis of caring to human beings was deliberated, thus prevents fragmenting into elements such as mind and body. Mostly if not all of the cases when a nurse cares for the person in a healthcare setting, only the physiologic needs and physical complaints of a person were treated. The care provider often fails to appreciate some other aspects of human being. As a result these aspects are neglected and assessed less. It was embedded in the CUEN theory that caring was innate in nursing.

The CUEN assumes that caring is a language of nursing. As such it is communicated that nursing is an act of holistic care. The theoretical assumptions are:

The persons are whole and complete beings who live in a caring environment from moment to moment;

Personhood is enhanced as persons participate and interact in a nurturing relationship between the nurse and the person being nursed;

Caring is expressed in nursing with unending caring. It distinctively focuses persons through the healing use of self in a compassionate way central to the day-to-day experience of the nursed-nurse relationship;

Caring as the unending expression of nursing considers that the intention of the practice of nursing helps in elevating persons living and growing in caring eviroment Boykin \& Schoenhofer (2001).

Nursing is crafted as "caring between" Boykin \&
Schoenhofer (2001) to understand the many facets of nursing situations.

Caring as Unending Expression of Nursing (please see Fig.1), shows how the nurse and the one nursed relate with each other thus producing the interface in a caring environment. In this illustration, nursing occurs when both (the patient and the nurse) interacts with each other. Before the interaction, the nurse comes to understand himself first and then care for a person in need of a therapeutic in a non-manipulating environment. In this manner the nursed individual establishes a trusting relationship with the health care provider.

\section{The Practice of Nursing}

The practice of nursing within this structure requires acknowledgment of oneself, especially in the light of practice environments, which depersonalize and support the notion of the nurse as the instrument and as a means to an end. In the acknowledgment phase, the nurse starts to critically observe and assess the patient not as integrative being, but as a holistic beingmore than the sum of its parts. The nurse comes into the avenues of the nursed with the aim of knowing more, establishing a relationship and sustaining connection as an unending expression of caring. Furthermore, the nurse understands the presence of the nursed, through appreciative inquiry, and as an active listener at the moment. That moment when the nurse starts to appraise the patient's presence through continuous interaction in a non-manipulating environment, this signals realizations of self for the nurses, as a being always involved in caring, and rediscovering opportunities in caring possibilities within the nursing situation. This freedom is the freedom to be with the patient, the freedom to decide to care and the freedom to unfold situations by both parties.

After the nurse acknowledged the patient's presence and had thoroughly assessed the need for the moment, then it is communicated through proper channels. Once the nurse completely realizes self as a person, who cannot fulfill complete caring, not able to transpire caring in the nursing situation, this must be articulated and shared. There would be times, when the patient may need not a nurse to assist him in his activities of daily living; instead, they (the patients) just want a companion or someone to talk to, or even when their perceived need at the moment is outside the scope of the nursing practice. In this case, communication and proper channeling of the essence of the message is necessary. 
The nurse upon the acknowledgment of the patient's needs at the moment will refer this concern to appropriate disciplines for proper action. Reentering this moment of caring through articulation or proper communication is another expression of caring that allows the nurse to bring substance and element to care and develop designs as evidence of a caring attribute that is both meaningful for both of them in a caring environment. Through communicating patient's concerns and listening to their stories in a caring environment, new possibilities arise for nursing in practice as a caring profession. Telling the patient faithfully of what the nurse objectively saw and perceived at the moment indicates valuing and honoring them. Respecting their beliefs and values in clear ways reaffirms the substance of nursing and refreshes the caring intention of the nurse.

As the nurse appreciates and communicates the needs of the moment, the nurse offers identifiedappropriate solutions so that the patient can make informed choices without compulsion or forcefully. In this phase, the nurse permits the patient to be enlightened on the different options readily available and alternatives in addressing the concern. The purpose is to make a reasoned choice by individuals, using relevant information about the advantages and disadvantages of all the possible courses of action, in accord with the patient's belief Jepson (2005). The nurse presents options to the patient for them to act intentionally with sound understanding and judgment, without controlling influences that determine their actions. The family members being part of the patient's support system must also be educated on the issues affecting the patient decision as they (the family members) protect and provide the patient's needs and additional resources.

As the nurse continuously interacts with the nursed and his support system, caring takes place in the nursing situation. The idea regarding the environment of nursing was formed when the nurse and the nursed "shared lived experience in which caring between" Boykin \& Schoenhofer (1993) enhances the personhood. When the nurse is ready to nurse the sick patient, then nursing situation come into existence Boykin \& Schoenhofer (2001). Therefore the practice and the practical knowledge of nursing are situated in the relational focus or the heart of person-with-person caring in the nursing situation. Offering options as the patient create informed choices for his betterment involves the expression of respecting values, intentions and actions that further strengthen the connection of nursing. In this manner, the lived relationship of a nurse and the patient were created and understood Boykin \& Schoenhofer (2000).

Further, the nurse and the nursed will conjointly advance to materialize the identified option made. The complete execution of the recognized intervention will come into play, signaling the fourth phase of the CUEN theory. This phase is the call for dual (the patient and the nurse) with the implementation of the identified answersto-their-problem. The impact of its implementation calls for quality improvement and healthcare transformation in alleviating patient's health status which underscores the need for redesigning care that is effective, safe and efficient. It is in this manner that the patient must receive quality healthcare from the nurse's perspective which further justifies the very reason for existence of nursing practice and the need for nurses. The Institute of Medicine in 2003 stipulated that the demand of individuals for health services will increase and the desired outcomes will become consistent with the modern knowledge of practice. This brings into focus three aspects of quality care as bases to check the degree of its implementation. First, are the services (the interventions identified), the targeted health outcomes and the consistency with current knowledge (evidencedbased). The idea further expresses an underlying belief that the continuous learning and conduct of investigation will produce desired health outcome and that a given strategy is effective. The alignment of professional knowledge through evidence-based practice is a means to obtain the goal to quality and is the success indicator for the entire phase of the interaction. However, if the identified solutions did not show expected outcome, then the process repeated making it cyclical and never-ending.

In the figure the arrow represents continuity and interconnectedness from one aspect of care to another. The arrows provide the nurse the opportunity to connect and understand the patient as he (the nurse) unceasingly search for meaning for both the patient and himself in every phase. Further, the arrows are placed in between the circles as it depicts the nursing situation, visualized the dynamism of caring that provides organizing purpose and integrated functioning. The arrows (Figure1) connect one phase to the other which suggests that the nurse may gather different ideas and 
notes from the patient as he (the nurse) searches for significance, but all complement in one accord being one in the circle.

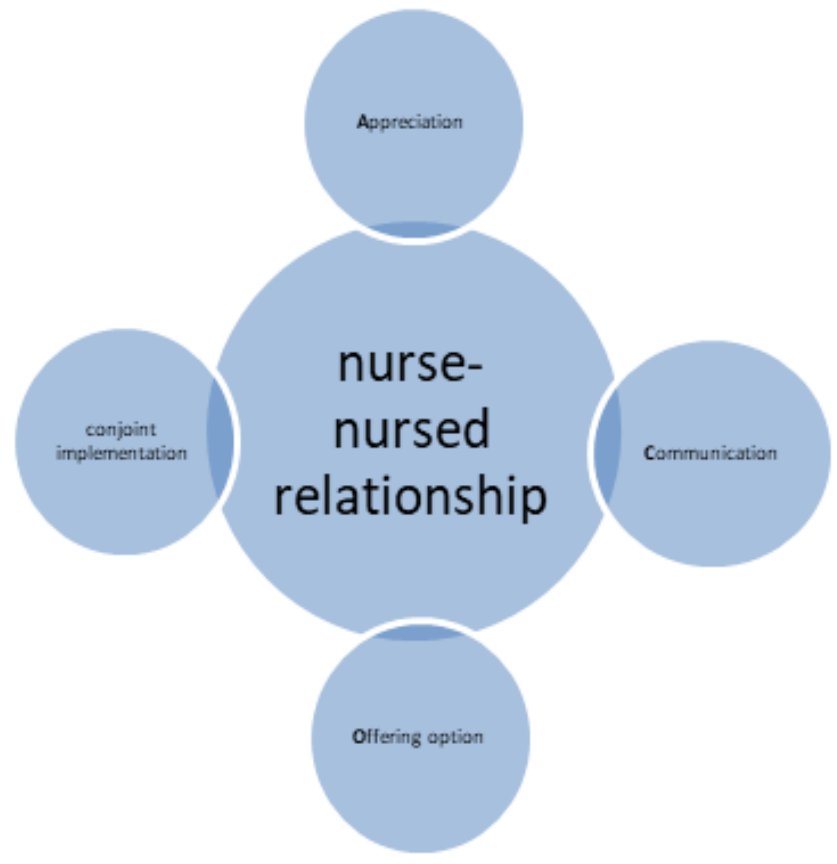

Figure 1: Caring as Unending Expression of Nursing.

The four smaller circles (see Fig.1) are slightly overlapping in the bigger circle at the middle. The framework can be interpreted as the four phases of interaction that exist only when the nurse and the nursed are interacting. No one can create the nursing situation except when the nurse and the patient intermingle with each other. The four phases of caring are irremovable and ineradicable. The nursing situation can only happen when both stakeholders (patientnurse) congregate; in like manner which sustains the movement, being invigorated by the interaction of caring.

The bigger circle (Figure1) speaks that the focus of every caring opportunity is an interaction between the nurse and the nursed. This interaction enhances the knowledge in particular and the development of a patient-nurse relationship. The experience developed during the interaction generates meaning for one's existence in a caring environment beyond and within their present situation of interaction. This is pivotal to the development of their relationship in the transforming community health care.

\section{CONCLUSION}

The theory entails that caring is innate to any human beings. Showing care may or may not be understood completely by its recipient or those who surrounds them. As a provider of care, expressing concerns is not limited to providing what the patient needs, but it should extend on educating the patient regarding important state of affairs. The duty of the nurse is to provide unending care towards patients. From the present study it is evident that caring is an unending expression of nursing establishing the theory under observation.

\section{REFERENCES}

Barnum, B.S. (1998). Nursing theory: analysis application and evaluation. $5^{\text {th }}$ edition. Lippincott, Philadelphia.

Boykin, A. \& Schoenhofer, S. (1993). Nursing as caring. A model for transforming practice. New York. National League for Nursing Press.

Boykin, A. \& Schoenhofer, S. (2000). Nursing as caring: An overview of general theory of nursing. In M. E. Parker (Ed.), Nursing theories and nursing practice. F. A. Davis, Philadelphia.

Boykin, A. \& Schoenhofer, S. (2001). The role of nursing leadership in creating a caring environments in health care delivery systems. Nursing Administration Quarterly, 25(3), pp 1-7.

Dickoff, J. \& James, P. (1968). Symposium on theory development in nursing. A theory of theories: A position paper. Nursing Research, 17(3), pp 197-203.

Fawcett, J. (1983). Hallmarks of success in nursing theory development. In: Chinn PL. Advances in nursing theory development. Aspen, Rockville, pp 3-17. 
Institute of Medicine (US) Committee on the Health Professions Education Summit (2003). Health Professions Education: A Bridge to Quality. Ann C. Greiner and Elisa Knebel (Eds). National Academies Press (US), Washington (DC).

Jepson, R.G., Hewison, J., Thompson, A.G. \& Weller, D. (2005). How should we measure informed choice? The case of cancer screening. Journal of Medical Ethics, 31(4), pp 192-196.

King, A.R. \& Brownell, J.A. (1976). The Curriculum and the Disciplines of Knowledge; a Theory of Curriculum Practice. Robert E. Krieger Publishing, Huntington, New York.

Meleis, A.I. (2003). Theoretical nursing: development and progress. $3^{\text {rd }}$ edition. Lippincott, Philadelhpia.

Morris, D.L. (1996). Middle range theory-role in education. In: Allen Holmes, L. M.; Lee, S. H.; Queen, M.T. (Eds.). Proceedings of the sixth Rosemary Ellis Scholar's Retreat - Nursing science: implications for the 21st century. Cleveland: Frances Payne Bolton School of Nursing of Case Western Reserve University, pp 19-37.

Peterson, C. (1977). Questions frequently asked about the development of a conceptual framework. Journal of nursing education, 16(4), pp 22-32. 